\title{
Violences et désirs dans l'œuvre de Koltès et dans le théâtre contemporain, sous la direction de Raymond MICHEL et André PETITJEAN
}

\section{Paola Perazzolo}

\section{(2) OpenEdition}

\section{Journals}

\section{Edizione digitale}

URL: https://journals.openedition.org/studifrancesi/12131

DOI: 10.4000/studifrancesi. 12131

ISSN: 2421-5856

\section{Editore}

Rosenberg \& Sellier

\section{Edizione cartacea}

Data di pubblicazione: 1 avril 2018

Paginazione: 168

ISSN: 0039-2944

\section{Notizia bibliografica digitale}

Paola Perazzolo, «Violences et désirs dans l'œuuvre de Koltès et dans le théâtre contemporain, sous la

direction de Raymond michel et André PETITJEAN», Studi Francesi [Online], 184 (LXII | I) | 2018, online dal 03 juillet 2018, consultato il 18 novembre 2021. URL: http://journals.openedition.org/studifrancesi/ 12131 ; DOI: https://doi.org/10.4000/studifrancesi.12131

Questo documento è stato generato automaticamente il 18 novembre 2021.

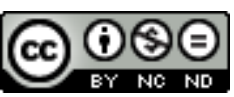

Studi Francesi è distribuita con Licenza Creative Commons Attribuzione - Non commerciale - Non opere derivate 4.0 Internazionale. 


\title{
Violences et désirs dans l'œuvre de Koltès et dans le théâtre contemporain, sous la direction de Raymond MICHEL et André PETITJEAN
}

\author{
Paola Perazzolo
}

\section{NOTIZIA}

Violences et désirs dans l'œuvre de Koltès et dans le théâtre contemporain, sous la direction de Raymond MICHEL et André PETITJEAN, Metz, CREM/Université de Lorraine, 2016, 216 pp.

1 Presentati durante la Journée d'études organizzata nell'ottobre 2014 nell'ambito della seconda Biennale Koltès tenutasi a Metz, la città natale del drammaturgo, i lavori qui riuniti si propongono di analizzare secondo approcci metodologici diversi la doppia tematica del desiderio e della violenza nella produzione in questione. André PETITJEAN (La violence verbale et les scènes de dispute dans l'œuvre de B.-M. Koltès, pp. 13-46) analizza le modalità linguistiche di espressione dell'aggressività verbale per mostrare come quest'ultima rappresenti una tematica onnipresente in un'opera che si rivela talmente costruita secondo una concezione agonistica delle relazioni interpersonali che «'on peut considérer la tension relationnelle comme l'un des marqueurs idiolectaux du dialogue koltésien» (p. 43). Anche Samar HAGE (Double-tranchant ou inanité de la parole dans le théâtre koltésien?, pp. 47-62) adotta un approccio linguistico e stilistico esaminando alcune scene conflittuali di Le retour au désert e di Dans la solitude des champs de coton per evidenziarne la ricorrenza e l'importanza. Nel caso di rapporti umani caratterizzati da un'aggressività che vanifica ogni possibilità di reale comunicazione, la «transcendance de la violence par la parole» (p. 53) consustanziale ad una scrittura prevalentemente argomentativa, si rivela essere unicamente un tentativo illusorio di sfuggire alla tragicità di un reale eternamente conflittuale rispetto al quale la sola via di 
fuga rimane la solitudine. In «Moi, j'écris des pièces qui ne sont ni profondes ni tragiques» (pp. 63-78), Florence BERNARD prende in considerazione l'aggressività rivolta contro se stessi. Il suicidio rappresenta per l'autore non un atto vittimistico da esibire in modo lirico o patetico, ma «le signe le plus spectaculaire de l'élan vital qui anime les personnages» (p. 77), veicolando in tal modo una rivendicazione libertaria trattata in modo quasi derisorio al fine di scardinare i codici di un teatro psicologico stanislavskiano o brechtiano che sia - considerato come riduttivo. Fred DALMASSo (Koltès et la violence du rythme, pp. 79-88) offre invece una lettura filosofica, sociologica e poetica degli effetti di sincope e di rottura quali appaiono a livello sintattico - incisi, frasi parentetiche, ecc. - e tematico-narrativo: secondo il critico, la rottura del ritmo di Dans la solitude des champs de coton acquista una valenza politica in quanto lo stato di vacatio retorica rinvia al tentativo autoriale di affermare l'inesistenza reale del soggetto politico e, conseguentemente, di contestare l'unità del discorso unico su cui si fonda la mondializzazione post-coloniale. Anche Raymond michel (Violence et désir dans "Dans la solitude des champs de coton" de Bernard-Marie Koltès ou deux êtres sous un ciel sans étoiles, pp. 121-168) si interessa alla pièce più nota del drammaturgo, di cui offre un'analisi puntuale e interessante. Dopo aver ricordato l'etimologia della parola cardine del testo - «désir» -, il critico sottolinea i rimandi intertestuali a livello di titolo e tematiche comuni - la violenza urbana o la tensione dei rapporti interpersonali - a Dans la jungle des villes di B. Brecht, cui il testo in questione si apparenta per poi discostarsene nell'affermazione dell'universalità del desiderio, come dimostrano le varianti proposte dalle tre storiche messe in scena di P. Chéreau. Per Michel, la forza della pièce koltésiana si basa sul fatto che il suo vero enjeu è una lotta per la vita che ingenera a sua volta un desiderio di riconoscimento. In L'antithèse imaginative comme incarnation de la violence et de l'expression du désir dans "Quai Ouest" de B.-M. Koltès (pp. 89-120), Galyna DRANENKO propone una lettura ermeneutica fondata sul concetto di «antitesi immaginativa» di Durand, evidenziando come le immagini simboliche notturne e diurne annuncino un'antitesi fondamentale - rinviando, rispettivamente, alla violenza della separazione o della sottrazione e al desiderio della completezza o della sublimazione - che si rivela essere in realtà una semi-antitesi: fondamentalmente, la predilezione assoluta per una notte disforica si oppone alla sostanziale assenza di una luce diurna solamente vagheggiata.

2 Concludono il volume i lavori di Jean-Paul DUfiet (Le traumatisme du génocide des juifs dans le théatre de Jean-Claude Grumberg, pp. 169-200) e dello psicanalista e psichiatra Jean-Richard FREYMANN (Quelle est la part de violence dans le désir?, pp. 201-216). Se quest'ultimo introduce a livello più generale le tematiche principali del volume contestualizzandole nell'opera del drammaturgo alsaziano, il primo estende la riflessione sulla brutalità alla produzione di un altro autore del xx secolo che si è molto occupato - e non solo per ragioni autobiografiche - della deportazione degli ebrei e del loro sterminio: la produzione in questione concorre a mettere in scena gli effetti della violenza della Storia e i traumi conseguenti, come si evince dall'analisi delle forme della scrittura drammatica, delle situazioni in cui sono inseriti i personaggi e della loro configurazione tematica.

3 Malgrado alcuni aspetti di incuria formale, il volume in questione si rivela interessante sia per la molteplicità degli approcci metodologici adottati che per la puntualità di alcune delle analisi presentate, fornendo spunti stimolanti per gli studiosi di un 
drammaturgo caratterizzato da una scrittura e da una Weltanschauung complesse e originalissime. 